\title{
Absence of Wharton's jelly: an association with feto-maternal morbidity
}

\author{
Swati Trivedi $^{1 *}$, Lata Ratanoo ${ }^{1}$, Shivani Purohit ${ }^{1}$, Prasoon Rastogi ${ }^{2}$
}

\begin{abstract}
${ }^{1}$ Department of Obstetrics and Gynecology, S. M. S. Medical College, Jaipur, Rajasthan, India
${ }^{2}$ Department of Medicine, King George Medical University, Lucknow, Uttar Pradesh, India
\end{abstract}

Received: 15 January 2020

Accepted: 06 February 2020

\author{
*Correspondence: \\ Dr. Swati Trivedi, \\ E-mail: krishnaagnihotri.kgmc@gmail.com
}

Copyright: () the author(s), publisher and licensee Medip Academy. This is an open-access article distributed under the terms of the Creative Commons Attribution Non-Commercial License, which permits unrestricted non-commercial use, distribution, and reproduction in any medium, provided the original work is properly cited.

\begin{abstract}
Umbilical cord contains two arteries and one vein connecting fetus to the placenta and is responsible for blood flow between the two. It is surrounded by Wharton's jelly which is a gelatinous substance and functions as adventitia layer of umbilical vessels, thereby providing insulation and protection to the umbilical cord. Umbilical cord abnormalities are associated with poor perinatal outcomes. Very few cases of absent Wharton's jelly are reported in literature. Ours might be the $8^{\text {th }}$ one in which we did a lower segment caesarean section for meconium stained liquor but the baby died after 12 hours.
\end{abstract}

Keywords: Meconium stained liquor, Umbilical cord, Wharton's jelly

\section{INTRODUCTION}

Wharton's jelly is a gelatinous substance within the umbilical cord which acts as a protective structure for the umbilical vessels. Absence of Wharton's jelly around the umbilical arteries is very rare and may be associated with adverse perinatal outcome. Till now 7 cases have been reported to the best of our knowledge.

- $\quad 1^{\text {st }}$ case in 1961 by Bergman et al in which a segment of the umbilical arteries were devoid of their Wharton's jelly covering. ${ }^{1}$

- $\quad 2^{\text {nd }}, 3^{\text {rd }}$ and $4^{\text {th }}$ cases were reported by Labarrere et al described 3 cases of completely absent Wharton's jelly around the umbilical cord arteries but was present around the umbilical veins; all cases were of meconium stained term neonates who died shortly after birth in whom umbilical arteries were detached from the cord substance and were associated with acute fetal distress and perinatal death which may be due to compression of the unprotected vessels. ${ }^{2,3}$
- $\quad 5^{\text {th }}$ case reported by Thomson and Hoo. ${ }^{4}$

- $6^{\text {th }}$ case by Kulkarni et al. ${ }^{5}$

- $7^{\text {th }}$ case by Christiano et al. ${ }^{6}$

Here, it might be the 8th case report of absent Wharton's jelly.

\section{CASE REPORT}

Reporting a case of absent Wharton's jelly in a 22-yearold pregnant female at 38 weeks of gestation admitted in our hospital. Patient was referred for meconium stained liquor and leaking per vaginum for last 8 to 10 hours. Patient was G3P1+(1). She had one live issue $\left(1^{\text {st }}\right)$, a female child of 4 years delivered by caesarean section at 37 week of gestation and the indication was eclampsia with Fetal distress. $2^{\text {nd }}$ issue was a preterm vaginal delivery at 7 months gestational age, a female child, died at one day of life. (In second pregnancy there was no documentation of hypertensive disorder of pregnancy or any other risk factor). 
Patient's height was 5 feet 5 inch and weight was $105 \mathrm{~kg}$ (BMI $38.56 \mathrm{~kg} / \mathrm{m}^{2}$ ). On physical examination bilateral pitting pedal edema along with generalized edema (anasarca) was present; no other significant abnormality was found. In present pregnancy, patient was on a (regular) ANC checkup at other hospital and diagnosed as hypertensive at 36 weeks, was on Tab Labetalol $100 \mathrm{mg}$ $\mathrm{BD}$ and her BP was controlled since then. On admission her BP was $150 / 90 \mathrm{mmHg}$ and urine albumin +1 . Patient's all other investigations were within normal limits and no abnormality was detected in USG.

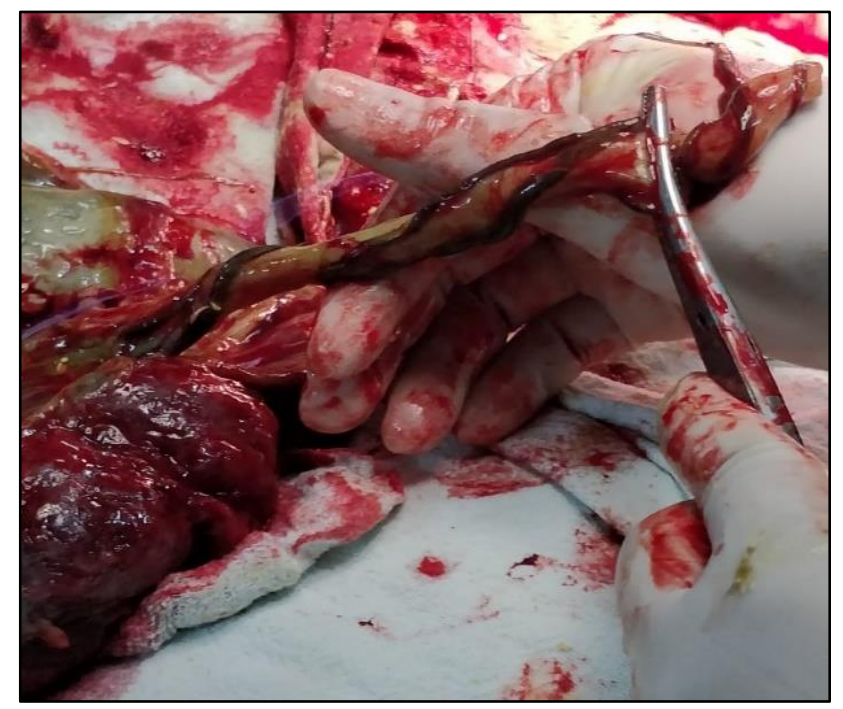

Figure 1: Gross examination at the time of delivery (caesarean section) showing absence of Wharton's jelly with umbilical arteries lying outside the umbilical cord.

Patient was taken for caesarean section in emergency for fetal distress and unfavorable bishop score, to deliver a male child of $2.0 \mathrm{~kg}$. Liquor was thick meconium stained; baby, placenta and cord were smeared with meconium. Wharton's jelly was absent along the entire length of umbilical arteries which were lying as two separate vessels outside cord (Figure 1). Umbilical cord was thin with length $52 \mathrm{~cm}$, site of insertion was normal and placental weight was $350 \mathrm{gm}$.

The general condition of the baby was low. The baby was small for gestational age (SGA) and had delayed cry at birth with Apgar score at $1 \mathrm{~min}$ and $5 \mathrm{~min}$ as 2/10 and $5 / 10$ respectively. Baby had perinatal asphyxia and respiratory failure leading to hypoxic ischemic encephalopathy (HIE) with shock. Baby was shifted to NICU and was taken on ventilation support and further management planned.

During NICU stay, the baby had an episode of seizure followed by cardiac arrest; CPR was attempted, but baby could not be revived and was declared dead after around 12 hours of life.

\section{DISCUSSION}

The umbilical cord is a structure that provides vascular flow between the foetus and the placenta. It contains two arteries and one vein which are surrounded and supported by gelatinous tissue known as Wharton's jelly (substantia gelatinea funiculi umbilicalis). ${ }^{7}$

Wharton's jelly is made up of mucopolysaccharides (hyaluronic acid and chondroitin sulphate), fibroblasts and macrophages. Hyaluronic acid (70\%) is an important molecule for the mechanisms of diffusion and osmosis in the umbilical cord. This structure gives elasticity to the umbilical cord, thus the main function of Wharton's jelly is the protection of the umbilical blood vessels by neutralizing the external pressure influence on blood flow between placenta and foetus. ${ }^{6}$ If Wharton's jelly is poorly developed, or if the vessels remain unprotected, they become more prone to compression. ${ }^{2,8}$

Wharton's jelly when exposed to temperature changes, collapses structures within the umbilical cord and thus provides a physiological clamping of the cord (an average of) 5 min after birth.

Structural abnormalities of the umbilical cord are conditions increasingly recognized, in literature, as being associated with foetal death in utero. The umbilical cord abnormalities that may cause damage to the foetal wellbeing includes rupture and thrombosis of the umbilical vessels, umbilical artery agenesis, and stenosis/obliteration/constriction of the cord, furcate and velamentous cord insertion, and absence of Wharton's jelly. These structural changes are strongly associated with intrauterine growth restriction, foetal death and increased rates of caesarean delivery. ${ }^{9-11}$ The quantitative alterations of Wharton's jelly have been linked to conditions such as gestational hypertension, smoking and prematurity. ${ }^{12}$ The extreme reduction of Wharton's jelly commonly named the 'Absence of Wharton's jelly' or 'insertio funiculi furcate', is a very rare lesion with which the literature has presented a suggestive relationship to meconium staining, low Apgar score, and stillbirths. In these cases, the insertion site is normal, but as the cord vessels lose the Wharton's jelly, their vessels become separated before reaching the placental surface. ${ }^{2,5}$

Raio et al, found an association between the presence of a thin umbilical cord and the delivery of an infant who is small for its gestational age. ${ }^{13}$ Similar relationship was found in our case as the baby, though weighed $2.0 \mathrm{~kg}$ and had thin Umbilical cord.

In our case the baby was Meconium stained with low Apgar score and died 12 hours after birth despite many resuscitative efforts. The three cases reported by Labarrere et al, were of meconium stained neonates who died shortly after birth in whom umbilical arteries were detached from the cord substance. But the relationship to meconium was disputed by Thomson and Hoo, who 
described a case of severely retarded child but without meconium stain in "linear disruption of the umbilical cord". ${ }^{2,4}$ Filiz et al, investigated the relationship between the amount of Wharton's jelly and its protective role in umbilical cord vessels, and hence, on foetal growth. Abnormal situations, such as a decrease in the hyaluronic acid content of Wharton's jelly and Wharton's jelly fibrosis, may affect the mechanical characteristics of the cord, which leads to impaired foetal circulation, anoxia, and foetal death. ${ }^{14}$

It had been suggested that this anomaly, absent Wharton's jelly, may be due to degeneration of Wharton's jelly around the vessels. An alternative explanation of this lesion is incomplete fusion of the amniotic covering and the mesenchyme of the umbilical cord during early development or a hypoplasia of amniotic covering with a secondary loss of the Wharton's jelly. ${ }^{5}$

\section{CONCLUSION}

The case we report here from our hospital is the first of its kind during the last 55 years period from 1965 to 2019 with an average of 22,000 deliveries per year.

As shown in other studies, our study also shows the association of absent Wharton's jelly with adverse perinatal outcome. The pathogenesis of absence of Wharton's jelly and its mechanism which affects foetus are to be studied further. There may be association of absent Wharton's jelly with hypertensive disorders of pregnancy and Intrauterine growth restriction/foetal growth restriction. More studies are needed to prove this.

Funding: No funding sources Conflict of interest: None declared

Ethical approval: Not required

\section{REFERENCES}

1. Bergman P, Lundin P, Malmstrom T. Mucoid degeneration of the Wharton's jelly: an umbilical cord threatening foetal life. Acta Obstet Gynecol Scand. 1961;40:372-8.

2. Labarrere C, Sebastiani M, Siminovich M, Torassa E, Althabe O. Absence of Wharton's jelly around the umbilical arteries: an unusual cause of perinatal mortality. Placenta. 1985;6:555-9.
3. Stevenson RE, Hall JG. Human malformations and related anomalies $2^{\text {nd }}$ edition Chapter 35; umbilical cord; 2005:1434.

4. Thomson LL, Hoo JJ. Linear disruption of umbilical cord: a rare anomaly of the cord associated with acute fetal distress and perinatal death/profound psychomotor retardation. Am J Med Genet. 1996;62:348-9.

5. Kulkarni ML, Matadh PS, Ashok C, Pradeep N, Avinash T, Kulkarni AM. Absence of Wharton's jelly around the umbilical arteries. The Indian J Pediatr. 2007;74(8):787-9.

6. Oliveira CC, Dufloth RM, Coelho KIR. Absence of Wharton's jelly: case report. J Bras Patol Med Lab. 2014;50(6):452-5.

7. Damasceno EB, de Lima PP. Wharton's jelly absence: a possible cause of stillbirth. Autopsy Case Reports. 2013;3(4):43.

8. Di Naro E, Ghezzi F, Raio L, Franchi M, D’Addario V. Umbilical cord morphology and pregnancy outcome. Eur J Obstet Gynecol Reprod Biol. 2001;96:150-7.

9. Benirschke K. Obstetrically important lesions of the umbilical cord. J Reprod Med. 1994;39(4):262-72.

10. Clausen I. Umbilical cord anomalies and antenatal fetal deaths. Obstet Gynecol Surv. 1989;44(12):8415 .

11. Sun Y, Arbuckle S, Hocking G, Billson V. Umbilical cord stricture and intrauterine fetal death. Pediatr Pathol Lab Med. 1995;15(5):723-32.

12. Barbieri C, Cecatti JG, Surita FG, Costa ML, Marussi EF, Costa JV. Area of Wharton's jelly as an estimate of the thickness of the umbilical cord and its relationship with estimated fetal weight. Reprod Health. 2011;8:32-7.

13. Raio L, Ghezzi F, Di Naro E, Gomez R, Franchi M, Mazor M, et al. Sonographic measurements of the umbilical cord and feftal anthropometric parameters. Eur J Obstet Gynecol Reprod Biol. 1999;83:135-45.

14. Filiz A, Rahine B, Keskin HL, Esra AK. Positive correlation between the quantity of Wharton's jelly in the umbilical cord and birth weight. Taiwan $\mathrm{J}$ Obstet Gynecol. 2011;50:33-6.

Cite this article as: Trivedi S, Ratanoo L, Purohit S, Rastogi P. Absence of Wharton's jelly: an association with feto-maternal morbidity. Int J Reprod Contracept Obstet Gynecol 2020;9:1318-20. 